\title{
ONLINE STUDENT ORAL CASE ANALYSIS DURING COVID-19 PANDEMIC: A CASE STUDY
}

\author{
Endin Nokik Stujanna ${ }^{*}$, Gea Pandhita ${ }^{1}$, Rizka Aries Putranti ${ }^{1}$, Bety Semara Lakshmi ${ }^{1}$, Wawang \\ Setiawan Sukarya ${ }^{1}$ \\ ${ }^{1}$ Faculty of Medicine, Prof. DR. Hamka Muhammadiyah University, Tangerang - INDONESIA
}

Submitted: 02 Dec 2020; Final Revision from Authors: 14 Apr 2021; Accepted: 23 Apr 2021

\begin{abstract}
Background: Currently, medical education program has implemented the student-centred education method by using Problem Based Learning (PBL) paradigm. One of its assessment methods is Student Oral Case Analysis (SOCA). This method determines the rhetorical and linguistic characteristics of students by using specific communication methods. An offline assessment is temporarily selected for the SOCA. Due to the pandemic, strict health protocols for medical education should be followed by any parties. As a result, there is a modification for learning method when offline (face-toface) activities should be shifted to online activities, includes SOCA assessment. However, in order to meet the objective of the learning, the modification needs careful planning and implementation. This study aimed to describe about how The Faculty of Medicine, Prof. DR. Hamka Muhammadiyah University (UHAMKA) successfully carried out SOCA assessment for their students through online method.
\end{abstract}

Case Discussion: During the outbreak of Covid-19 The Faculty of Medicine, UHAMKA, has changed SOCA assessment from offline mode to online mode by using Zoom application. Pre-exam preparation includes review of the questions by the Medical Education Unit team, preparation of human resources (examiners, supervisors), and supporting applications. The assessment is conducted by applying some adjustments between medical learning activities and current health protocols. Subsequently, upon completion of the assessment, an evaluation is conducted using a questionnaire and random interview technique.

Conclusion: The online method by using Zoom platform is evidently an effective option for SOCA assessment during the pandemic. It can be concluded that the exam successfully implemented to the student and it produced relatively similar results with an offline exam. The online SOCA assessment at Faculty of Medicine UHAMKA was well organized without any serious problem.

Keywords: online SOCA exam, PBL

*corresponding author, contact: endin_stujanna@uhamka.ac.id 


\section{PRACTICE POINTS}

- Student Oral Case Analysis (SOCA) assessment can be safely conducted by online method during this pandemic period.

- Several key factors for the success of online SOCA include: assessment tools, adequate numbers of examiners and supervisors, also plagiarism prevention.

- Online SOCA assessment is arranged by modifying and combining the offline exam mechanism and the application of online virtual room.

- The possibility of cheating as the most likely consequence of online SOCA, can be minimized by well-organized planning and detailed guidance for students, supervisors, and examiners.

\section{INTRODUCTION}

Student-centred education methods by using the Problem Based Learning (PBL) paradigm is commonly found in any medical school. The main feature of the method is known as a Tutorial. ${ }^{1}$ In addition to its significant role in the PBL paradigm, the tutorial may also improve the public speaking ability of students. ${ }^{2}$

Some assessment methods are used to evaluate Tutorial activities. The evaluation is needed to determine the achievement of students to meet standards of competency. One of the assessment methods is Student Oral Case Analysis (SOCA). ${ }^{2,3}$ This method introduced specific communication methods to determine the linguistic and rhetorical characteristics of students. ${ }^{2-6}$

Student Oral Case Analysis is considered as an important communicative activity in learning and evaluation mechanism for the students. It allows the students to professionally demonstrate their knowledge, communication skills, and scientific interactions. SOCA may helpfully support medical careers of students, as well as it trains the students to do analysis, make clinical decisions, and communicate the decision to patients or their families. Some studies indicated that SOCA can increase students' motivation to learn and analyze medical cases. ${ }^{2-4,7,8}$

Since the outbreak of the COVID-19, there are some drastic changes for most sectors, including the Medical Education sector. Medical education should deal with unpredicted challenges that never imagined before. The compulsory to follow health protocols, especially physical and social distancing policy, has encouraged the medical school to shift the learning method from previously offline method to newly online method. It is surely purposed to facilitate the learning process during the pandemic situation. ${ }^{9}$

Amongst the learning process in medical school, SOCA exam is regarded as one of complex activity. Before the pandemic, the exam is regularly carried out through offline method. Since there is a shifting of the method to online learning, the exam surely needs some adjustments, detailed planning, careful preparation and supervision. ${ }^{3,4,7}$ The Faculty of Medicine, UHAMKA, is a medical school which successfully conducted the online method of SOCA during the pandemic. Therefore, this article will find out about how the Faculty of Medicine, UHAMKA performed online method for SOCA assessment.

\section{CASE DESCRIPTION}

\section{An overview of SOCA Assessment}

SOCA provides significant benefit as a verbal test, because of its ability to evaluate the knowledge of the students and monitor plagiarism in written test. However, SOCA also have some weaknesses, including the subjectivity by examiner. ${ }^{3}$ Therefore, the presence of two examiners is needed to avoid subjectivity assessment. ${ }^{4}$ The standard deviation between the two examiners should not more than $20 \%$. For a total of 100 points, the scores should not differ more than 15 points. 
The mechanism of SOCA assessment at faculty of medicine, UHAMKA is started by determining the Learning Outcome for question, creating a scenario, and preparing an assessment rubric. The appointed medical experts will draft the learning outcome of scenario and rubric by referring to Indonesian Doctor Competency Standards (SKDI). The draft will be discussed with Medical Education Unit (MEU) to confirm its compatibility with SKDI. Finally, the approval from the Dean of the faculty is required.
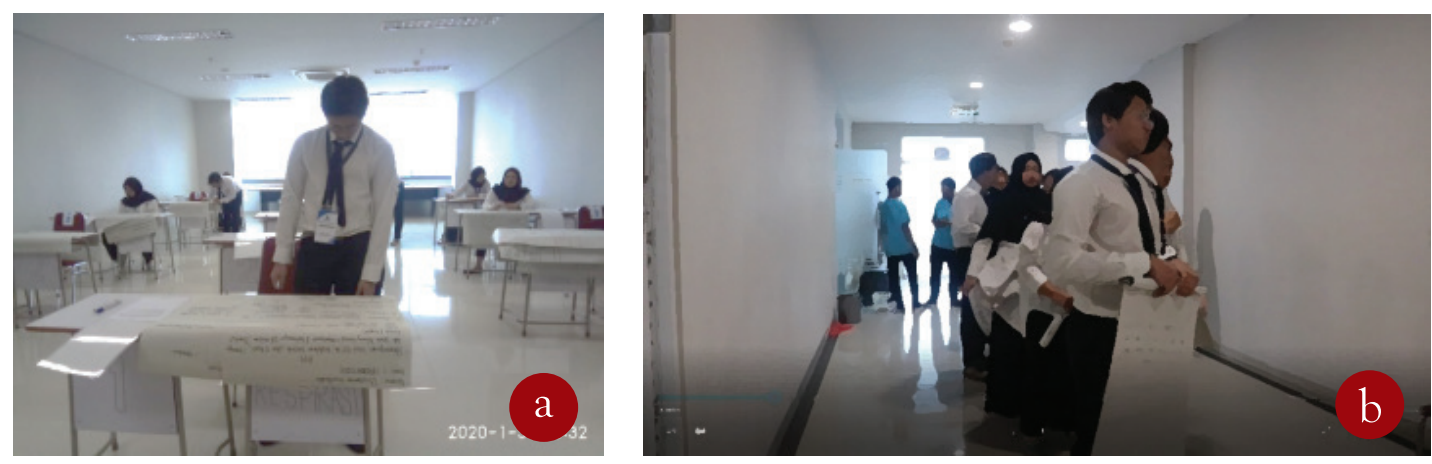

Figure 1. (a) Students answering the tasks in the Questioning and Presentation Preparation Room; (b) Students ready to enter the Presentation Room
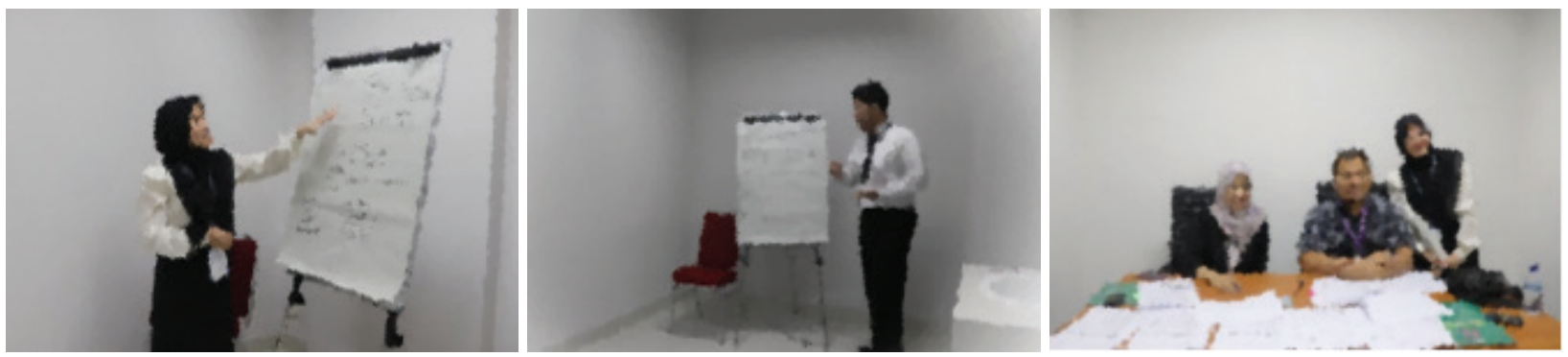

Figure 2. Students presenting their paper in the Presentation Room

\section{Online SOCA Assessment mechanism}

Online SOCA assessment at the Faculty of Medicine, UHAMKA was carried out by using Zoom pro or business application. This application was primarily selected because it is more familiar for students and teachers. Moreover, its breakout room feature applies to the SOCA exams.

Based on number of rooms required, the Zoom account was divided into several rooms/breakout rooms (Figure 3). The room refers to virtual room that has been adjusted to represent the design of offline SOCA assessment. The room consists of Quarantine room, a Questioning and Presentation Preparation Room, and a Presentation room.

Each student was registered as a co-host of the zoom meeting, since it allowed them to directly move to other virtual room, following the procedure of the SOCA assessment. Three lecturers were also registered as co-hosts because they responsible to monitor each room. One host was assigned to monitor the entire SOCA assessment. The procedures for the online SOCA assessment at UHAMKA Faculty can be seen as below:

1. Students joined the first breakout room which is called the Quarantine room 1. In this room, students randomly picked questions and queue number for the assessment.

2. According to draws result, the first group of ten students entered the second room, namely the Questioning and Presentation Preparation Room. Students had a maximum twenty minutes to solve the questions. There were ten breakout rooms in this session. Each breakout 
room has one supervisor. The supervisor shared the questions through the screen share option and responsible to monitor the students. Prior to the test, the supervisor informed about the guidance and rules, specifically related to the stationery (markers) for the presentation. It is aimed to prevent any fraud during the test. (Note: Students use laptops for Zoom access, and prepare a mirror next to the answer sheet/ presentation sheet. The mirror should reflect the display of the laptop (Figure 4.))

3. The member of the first group then respectively entered the third room namely the Presentation Room (ten different breakout rooms). Students made a presentation for ten minutes. Two examiners evaluated the presentation in each breakout room. Next, the examiners provided comments and feedback for ten minutes. Finally, they filled out an assessment rubric using the google form and the students were allowed to leave the room.

4. In the meantime, ten students of the second group entered the Breakout Room (Questioning and Presentation Preparation) to complete the task.

5. Other Students followed similar procedures as the first group until complete the assessment.

6. The first group who already completed all presentations, entered the fourth room, namely the Quarantine room 2. Students were not allowed to leave the room until all students finished the assessment.

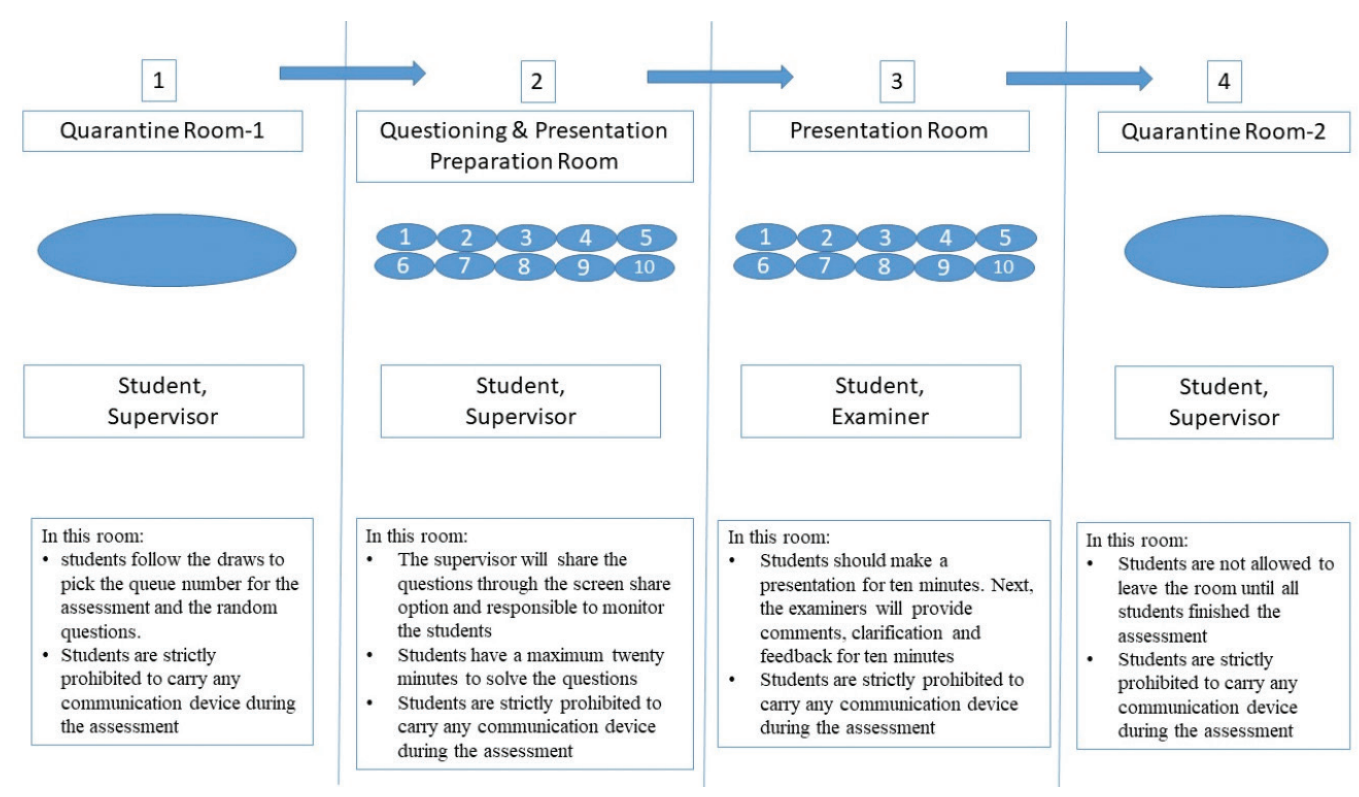

Figure 3. The flow of Online SOCA Assessment

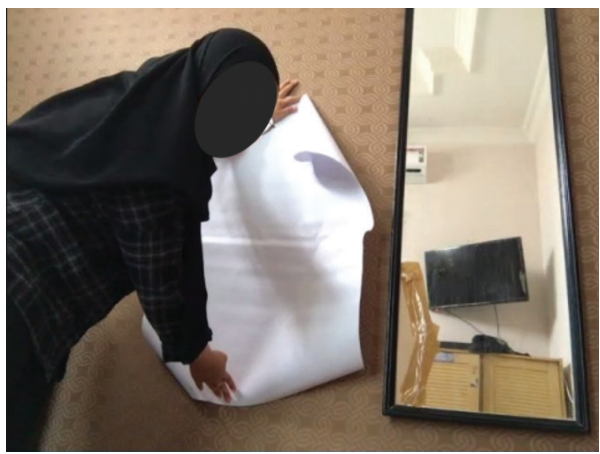

Figure 4. Students prepared Presentation Sheets in the Presentation Room
Regulations for the participants of the SOCA can be described as follows:

1. Examiners and Students are strictly prohibited to carry any device during the assessment.

2. The maximum gap of score between two examiners should not more than 15 (fifteen) points (total score of one hundred points).

\section{DISCUSSION}

SOCA has a significant advantage as a verbal test, Because of its ability to evaluate the knowledge of the 
students. In addition, SOCA is also used to monitor plagiarism in written assessments, both for multiple choice and/or essays. ${ }^{11,12}$ There are five provisions that must be considered in the assessment method..$^{13,14}$ Therefore, in order to reflect faculty of medicine, UHAMKA's concern about the requirements for good examination in the SOCA assessment, aspects that must be considered include:

- Validity, the SOCA questions should be reviewed by the Medical Education Unit (MEU) team, consisting of education and scientific experts.

- Reliability, the presence of two examiners will be needed to minimize or avoid subjectivity assessment. The deviation scores between the two examiners should not more than $20 \%$.

- Feasibility, we use a paid Zoom application in order to conduct SOCA assessments without worrying about interruptions while conducting examinations or limitations on the number of participants. There are 20 examiners and 12 supervisors for each assessment, in order to ensure that they are well-implemented. Exam participants are given directions regarding the security regulations; preparing their device, a mirror in front of their device, and three colored markers (the color of the marker used to complete the assessment is decided while the participants work on the case). These methods are used to reduce cheating.

- Acceptability, we used the questionnaire method for examiners and the random interview method for students to evaluate the results of implementing the SOCA assessment and determined that there were no issues in implementing the SOCA assessment online.

- Educational Impact, through the SOCA assessment students are trained and accustomed to analyzing cases and comprehensively solving problems/cases that require a high order level of thinking, as well as being able to manage cases not only symptomatically, but also causatively.

Moreover, the SOCA assessment is used to examine students' ability to analyze a case and solve a problem/ case completely. The SOCA assessment conducted at faculty of medicine, UHAMKA is formative and summative. It is formative in that examiners provide feedback to the exam participants and summative in that it is a component of the block assessments with a weighting of $15 \%$ of the total block components. It is important to apply SOCA assessments as, in addition to being used to evaluate students' learning outcomes, they can be used to assess exam participants' high order thinking level abilities, in that the SOCA assessment trains medical students to be accustomed to always comprehensively analyzing a problem in conducting problem solving.

At faculty of medicine UHAMKA, the SOCA assessment was conducted with two batches, 2018 (n $=46)$ and $2019(n=20)$. In each exam, there were 20 examiners and 12 supervisors involved. It is crucial to evaluate the implementation of the assessment. Therefore, the implementation of the SOCA assessment at faculty of medicine UHAMKA was evaluated immediately after the completion of the examinations. Examiners $(n=20 / x$ exam) conducted an evaluation using the questionnaire method. The questionnaire evaluating the completed SOCA assessment then produced qualitative evaluation results. In addition to the examiners, the students also conducted an evaluation of the SOCA assessment using the random interview method $(\mathrm{n}=10$ for students from the 2019 batch and $n=25$ for students from the 2018 batch). The online SOCA assessment at UHAMKA Faculty Of Medicine was successfully conducted without any serious problem. According to the statements from the students, examiners, and staffs, there were relatively no substantial obstacle during the exam. The results also indicated that there is no significant difference between online and offline assessment related to the evaluation of the student's abilities.

Some factors can be identified as potential for the improvement of online SOCA assessment: (1) good communication before and during the assessment, (2) rehearsal and practice before the assessment is strongly recommended. The rehearsal should be attended by all participant of the assessment, as well as all supporting staff, (3) good preparation for the electronic devices (internet networks and compatible software), and (4) good teamwork and discipline by all participant to follow the rules (time discipline). 
Despite the successful result, there are some obstacles can be found during the assessment were: (1) unstable internet network, and (2) lack preparation for the electronic devices and gadgets (including the software/application). In order to prevent the possibility of the unstable internet network, the examiners and support staff asked to come to campus during the assessment (campus has good internet connection). However, they should follow strict health protocols.

\section{CONCLUSION}

The online method for SOCA assessment by using the Zoom application can be a recommendable option during the pandemic. The assessment is conducted by applying some adjustments between medical learning activities and current health protocols. Finally, it can be concluded that the assessment is successfully implemented to the student and it also produced relatively similar results with the offline exam.

\section{RECOMMENDATION}

Further studies are still needed, especially related to internet network problems in student residences, and preventive measures to anticipate the possibility of fraud.

\section{ACKNOWLEDGEMENT}

The authors would like to thank to all supporting staffs at the Faculty of Medicine, UHAMKA for technical assistance during SOCA assessment in Faculty of Medicine, UHAMKA.

\section{COMPETING INTEREST}

The authors declare that there are no competing interests related to the study

\section{AUTHORS' CONTRIBUTION}

Endin Nokik Stujanna - developing research proposal, developing method details, developing technical case details and publication manuscript.
Gea Pandhita - developing research proposal, developing technical case details and publication manuscript.

Rizka Aries Putranti - developing method details.

Bety Semara Lakshmi - developing technical case details.

Wawang Setiawan Sukarya - developing technical case details.

\section{REFERENCES}

1. Joughin G, Leeds Metropolitan University., University of Wollongong. A short guide to oral assessment. 2010; (January 2010):23. Available from: http://eprints.leedsbeckett.ac.uk/2804/

2. Sari SM. Validitas dan Reabilitas Metode Penilaian Students Oral Case Analysis (SOCA) pada Mahasiswa Tahap Sarjana Kedokteran. 2013;2(2):97-100.

3. Putranti RA, Emilia O, Suryadi E, Kedokteran DP, Kedokteran F, Gadjah U. Validitas dan Reliabilitas Ujian SOCA (Students Oral Case Analysis): Studi di Salah Satu Fakultas Kedokteran di Indonesia. Validitas dan Reliab Ujian SOCA (Students Oral Case Anal Stud di Salah Satu Fak Kedokt di Indones. 2016;5(3):148-56.

4. Jayawickramarajah PT. Oral examinations in medical education. Med Educ. 1985 Jul;19(4):290-3.

5. Heiman HL, Uchida T, Adams C, Butter J, Cohen E, Persell SD, et al. E-learning and deliberate practice for oral case presentation skills: A randomized trial. Med Teach. 2012;34(12).

6. Daniel M, Rencic J, Durning SJ, Holmboe E, Santen SA, Lang V, et al. Clinical Reasoning Assessment Methods: A Scoping Review and Practical Guidance. Acad Med. 2019;94(6):90212.

7. Wardoyo EH, Syahrizal BM, Purnaning D, Widiastuti IAE, Ekawanti A, Wajdi MF. Introduction of Student Oral Case Analysis (SOCA) to Assess Student's Performance in Pre-clinical Setting in Faculty of Medicine, Mataram University. Cermin Dunia Kedokt. 2010;179(August):434-6. 
8. Schneider JR, Sherman HB, Prystowsky JB, Schindler N, Darosa DA. Questioning skills: The effect of wait time on accuracy of medical student responses to oral and written questions. Acad Med. 2004;79(10 SUPPL.).

9. Foster K. Ayittey, Ayittey MK, Chiwero NB, Kamasah JS, Dzuvor C. Economic impacts of Wuhan 2019-nCoV on China.pdf. 2020. p. 473-475.

10. Joughin G CG. Oral assessment. Biomed Sci. 2003;47(10):1078-80.

11. Melvin L, Rassos J, Panisko D, Driessen E, Kulasegaram KM, Kuper A. Overshadowed by Assessment: Understanding Trainee and Supervisor Perspectives on the Oral Case Presentation in Internal Medicine Workplace-Based Assessment. Acad Med. 2019;94(2):244-50.
12. Kakar SP, Catalanotti JS, Flory AL, Simmens SJ, Lewis KL, Mintz ML, et al. Evaluating oral case presentations using a checklist: How do senior student-evaluators compare with faculty? Acad Med. 2013;88(9):1363-7.

13. Van Der Vleuten CPM. The assessment of professional competence: Developments, research and practical implications. Adv Heal Sci Educ [Internet]. 1996;1(1):41-67. Available from: https://doi.org/10.1007/BF00596229

14. Rauf L. Case-Based Discussion in United Kingdom General Practice Training: A Critical Analysis. Cureus. 2021;13(2). 